\title{
Abscess Leakage
}

National Cancer Institute

\section{Source}

National Cancer Institute. Abscess Leakage. NCI Thesaurus. Code C40418.

The loss of a fluid from an abscess into the surrounding tissue or body cavity. 